\title{
Pearls \& Oy-sters: Number, Weaker, and Dizzier Due to Transthyretin Amyloidosis After 2 Liver Transplants
}

Alexan I. Yerevanian, MD, and Francy Shu, MD

Neurology ${ }^{\circledR}$ 2021;96:e1088-e1091. doi:10.1212/WNL.0000000000011289
Correspondence

Dr. Shu

fshu@mednet.ucla.edu

\section{Pearls}

- Hereditary transthyretin amyloidosis (hATTR) is an autosomal dominant, rapidly progressive, multisystem disease with substantial clinical heterogeneity, typically marked by lesions in the peripheral nervous system (median neuropathy, sensorimotor polyneuropathy, small-fiber somatic and autonomic neuropathy) and cardiovascular system.

- Delay in diagnosis and treatment is common because patients may present with vague symptoms such as dizziness and numbness.

- Traditional disease-modifying therapies included liver transplantation and transthyretin (TTR) stabilizers. Recent advances in oligonucleotide drugs offer new promises in the treatment landscape.

\section{Oy-sters}

- Recipients of a domino hATTR liver can develop analogous neurologic manifestations as early as several months to years after the transplantation; the symptoms could worsen despite retransplantation from a healthy donor to replace the first transplanted amyloidogenic liver.

- Paradoxical wild-type TTR deposition after liver transplantation can result in significant neurologic, cardiac, gastrointestinal, and pulmonary burdens.

- The advent of new disease-modifying therapies and the option of repeat liver transplantation necessitate stringent surveillance for neurologic symptoms and signs to prevent or delay neurologic deteriorations.

A 61-year-old woman, a former ballerina, presented to our clinic for evaluation of numbness and weakness, along with complaints of dizzy spells, dry eyes, dry mouth, chronic cough, solid dysphagia, persistent constipation, and generalized hypohidrosis.

At age 43, the patient was diagnosed with hepatitis B and hepatocellular carcinoma, for which she received an orthotopic liver transplant in the same year. The donor was known to have a glycinefor-glutamic acid substitution mutation at codon 54 (Glu54Gly) of the TTR gene. In a riskbenefit discussion, the patient was informed that it would be 3 decades before the symptoms of TTR amyloidosis such as mild numbness would manifest, so she agreed to liver transplantation.

Five years after the transplantation, she noticed numbness and weakness in her toes. She found herself tripping over her son's toys, could no longer wear high heels, and could no longer jeté in ballet. Gradually, her weakness worsened and involved her hands such that it became taxing to open a water bottle and impossible to hold her children. Her hands felt swollen and her joints stiff. She had difficulty climbing stairs, necessitating the grabbing of a handrail or her husband's belt.

With time, the patient developed persistent diarrhea. She felt palpitations and became dyspneic when walking long distances. Her systolic blood pressure ranged from the 60 s to 160 s over a few 
hours. Chronic diarrhea transitioned into constipation. She became dizzy when changing position and after eating. For each meal, she was quick to vomit and needed 1 hour to chew food with liquid to combat early satiety and dry mouth. She used lubricating drops for xerophthalmia. Stomach and colorectal biopsies revealed histologic evidence of TTR amyloidosis. Liquid chromatography tandem mass spectrometry (LC-MS/ MS) of her subcutaneous abdominal fat aspirate specimen detected peptide spectra consistent with 2 isoforms of TTR: the wild-type and the pathogenic TTR Glu54Gly variant.

Nine years after the transplant, given symptom progression, the patient received a second liver transplant from a heathy donor, but continued to deteriorate, albeit at a slower rate. She developed generalized hypohidrosis and cold intolerance. Her explanted liver transplant stained by Congo red and crystal violet confirmed the presence of amyloid in the liver and the nerves and vessels of the porta hepatis and portal tracts.

The patient developed dysphagia and underwent esophagogastric junction dilation. Three years after the retransplant, her gastric biopsy revealed extensive Congo red highlights consistent with amyloid deposition. Another three years after that, LC-MS/MS on another stomach specimen detected a peptide profile consistent with TTR amyloid deposition, without an amino acid sequence abnormality, mostly consistent with age-related amyloidosis.

The patient's neurologic examination demonstrated moderate upper extremity weakness in bilateral deltoids and triceps and moderate lower extremity weakness in bilateral iliopsoas, tibialis anterior, gastrocnemius, soleus, plantaris, flexor hallucis longus, and flexor digitorum longus. She had no strength in extensor digitorum longus on either side. She demonstrated allodynia in her soles on pinprick and diminished sensation up to mid-feet and fingertips. Vibratory sensation was diminished up to the knees, with more loss on the right. Proprioception in the toes was mildly impaired. Reflexes were reduced in the biceps and patellae bilaterally and absent in the triceps, brachioradialis, and ankles bilaterally. She had difficulty walking on her toes, heels, and in tandem. Gowers sign was present.

Blood testing including hemoglobin $\mathrm{A} 1 \mathrm{C}$, vitamins $\mathrm{B}_{12}$, $\mathrm{B}_{1}$, and $\mathrm{E}$, zinc, serum protein electrophoresis, serum immunofixation, creatine kinase, thyroid-stimulating hormone, and C-reactive protein was normal. Hepatitis B surface antigen has been persistently nonreactive since 2006. Serology of anti-SSA/SSB, thyroglobulin, thyroid peroxidase, antineutrophil cytoplasmic antibodies, gliadin, transglutaminase, endomesial immunoglobulin A, cryoglobulin, paraneoplastic panel, gait ataxia late onset polyneuropathy syndrome-related antibodies, and sensorimotor neuropathy profile with Recombx-Complete was negative. Sequence analysis and deletion/duplication testing of 72 genes including TTR in Invitae comprehensive neuropathy panel was negative. Nerve conduction study (NCS) and electromyography demonstrated evidence of a significant, length- dependent, sensorimotor, axonal polyneuropathy with active denervation and chronic reinnervation changes.

Despite treatments with diflunisal for 8 years and doxycycline for 3 years, NCS/electromyography demonstrated mostly unelicitable sensory and motor responses in the legs and notably reduced sensory and motor responses in the arms. We planned a sural nerve biopsy but aborted the plan because an excision would inevitably result in permanent sensory deficits. Cardiac MRI demonstrated atrial septal thickening and chest CT showed interstitial edema, consistent with cardiac and pulmonary amyloidosis, respectively. The patient also developed atypical atrial flutter and persistent atrial fibrillation necessitating cardiac ablation and direct current cardioversion twice. She was recently admitted for profound orthostatic hypotension but responded to treatment with IV fluid and oral midodrine.

\section{Discussion}

hATTR is an autosomal dominant, rapidly progressive, multisystem disease with substantial clinical heterogeneity, typically marked by lesions in the peripheral nervous and cardiovascular systems. It is the most common form of hereditary amyloidosis, also known as familial amyloid polyneuropathy. ${ }^{4,5}$ More than 130 mutations in the TTR gene have been identified, with 3 major phenotypes: predominantly neurologic, predominantly cardiac, or mixed. ${ }^{7}$ Variations in clinical presentations are common even for the same pathogenic variant in the same family. Cardinal neurologic features include somatic neuropathies such as bilateral median neuropathies, or carpal tunnel syndrome, small fiber neuropathy characterized by burning pain, and length-dependent sensorimotor axonal polyneuropathy manifesting as numbness and weakness in the feet. ${ }^{4}$ In addition, autonomic neuropathies affecting the cardiovascular, gastrointestinal, genitourinary, sudomotor, and glandular systems can severely impair simple activities such as getting up from a chair or having a bowel movement. Moreover, cardiomyopathy typically progresses to heart failure, necessitating a heart transplant. Furthermore, TTR amyloid may deposit in the lungs, spleen, kidneys, eyes, adrenal glands, and thyroid gland. ${ }^{5}$ hATTR manifests in the third to sixth decade of life, but some genotypes have low penetrance with a certain percentage remaining asymptomatic. See the figure for an illustration of the multisystemic nature of hereditary and wild-type TTR amyloidosis.

As $95 \%$ of TTR is produced in the liver, ${ }^{5}$ orthotopic liver transplant has been used as a treatment for hATTR. There is evidence that this can stabilize sensorimotor neuropathy and improve autonomic neuropathy. ${ }^{4}$ Histologically, amyloid deposits in visceral tissue are notably decreased after liver transplantation. ${ }^{4}$

Although the liver is the main source of TTR, the liver itself is spared and hepatic failure does not occur in patients with hATTR $^{5}$ Transplantation of livers from hATTR-positive donors has been considered when prospective recipients with other liver diseases would otherwise have a long wait or are seeking palliation 


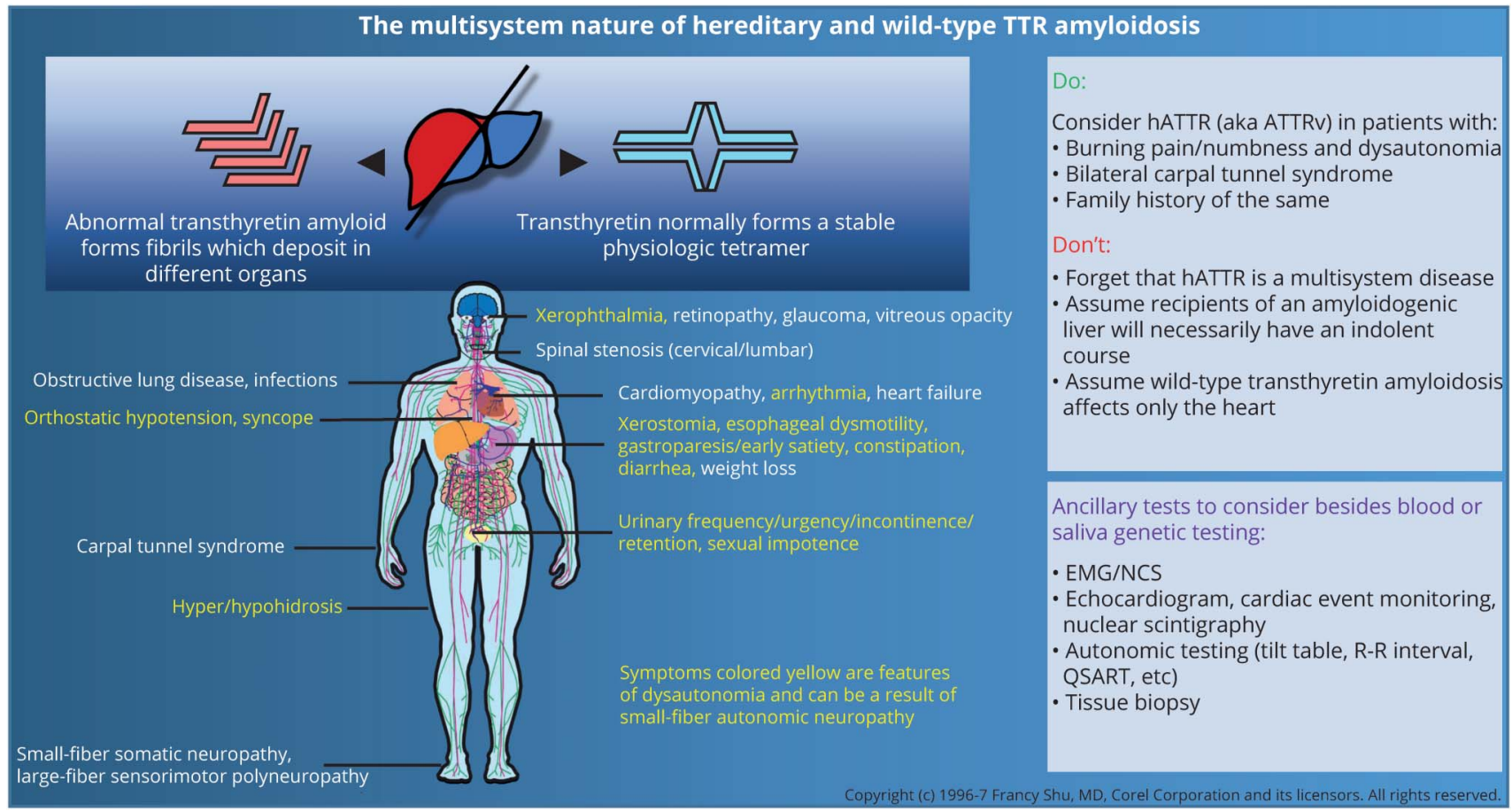

Hereditary transthyretin amyloidosis (hATTR) is an autosomal dominant, rapidly progressive, multisystem disease with substantial clinical heterogeneity, typically marked by neuropathy and cardiomyopathy. EMG = electromyography; NCS = nerve conduction studies.

rather than long-term cure. This is known as a sequential, or domino, liver transplant and has the advantage of addressing organ shortage and allowing transplantation with less ischemic time. ${ }^{1}$ Patients also have the option of retransplantation in the future. ${ }^{5}$

Despite such a postulated positive outlook, a 2010 study of 17 patients who underwent domino liver transplantation identified 4 patients who subsequently developed systemic TTR amyloidosis, demonstrating the transmission of the abnormal TTR protein to recipients. ${ }^{1}$ There are also reports of paradoxical worsening of cardiomyopathy following liver transplantation. ${ }^{2}$ In our case, after the first transplant, the patient developed painful feet, intermittent diarrhea, weight loss, dry cough, orthostatic lightheadedness, blurry vision, and occasional palpitation.

The patient received a second liver transplant but continued to decline. Even though the source of the abnormal TTR, the first transplanted liver, was already removed, the patient continued to exhibit features of TTR amyloidosis, despite testing negative for a pathogenic germline variant.

The patient's clinical picture, the spectrometric presence of the wild-type isoform, the histologic evidence of the gastric TTR, and the electrodiagnostic and radiologic findings from the nerves, heart, and lungs, as well as the lack of proof of other etiologies from an extensive list, all suggest the paradoxical pathologic effect of multisystemic amyloidosis from wild-type TTR. The lingering residual mutant TTR aggregates as remnants from the first diseased domino liver might have catalyzed the tetrameric dissociation, proteolytic cleavage, and aberrant aggregation of the wild-type isoforms, as the mechanism of pathologic deposition is similar for both mutant and wild-type proteins. ${ }^{8}$ This lingering residual model might also explain the further decline in some of the patients with germline TTR mutations despite liver transplantation. ${ }^{2}$

Conventional treatments such as diflunisal, a traditional stabilizer, and doxycycline, a fibril disruptor, have been used for stabilization of cardiac amyloidosis. ${ }^{9}$ Recent treatment advances including Food and Drug Administration (FDA)approved hATTR silencers such as patisiran and inotersen to inhibit the production of the protein could be considered, particularly as both also target wild-type mRNA. ${ }^{7,8}$ Tafamadis, a newly FDA-approved stabilizer to protect the physiologic tetrameric form of TTR, may also be considered to prevent the formation of the pathogenic amyloid fibrils. ${ }^{10}$

Our case highlights the short latency (as early as 5 years) for a domino hATTR liver recipient to develop analogous neurologic and systemic complications. Secondly, paradoxical wildtype TTR aggregation and deposition after liver retransplantation can result in significant neurologic, cardiac, gastrointestinal, and pulmonary burdens. Stringent surveillance is necessary and new therapies could be beneficial to minimize and delay neurologic deteriorations from TTR amyloidosis. 


\section{Study Funding}

No targeted funding reported.

\section{Disclosure}

The authors report no disclosures relevant to the manuscript. Go to Neurology.org/N for full disclosures.

\section{Appendix Authors}

\begin{tabular}{lll}
\hline Name & Location & Contributions \\
\hline $\begin{array}{l}\text { Alexan } \\
\text { Yerevanian, } \\
\text { MD }\end{array}$ & $\begin{array}{l}\text { Division of Neuromuscular } \\
\text { Medicine, Department of } \\
\text { Neurology, UCLA Medical Center, } \\
\text { Los Angeles, CA }\end{array}$ & Fellow \\
\hline $\begin{array}{l}\text { Francy Shu, } \\
\text { MD }\end{array}$ & $\begin{array}{l}\text { Division of Neuromuscular } \\
\text { Medicine, Department of }\end{array}$ & $\begin{array}{l}\text { Supervising } \\
\text { physician/ } \\
\text { corresponding } \\
\text { author }\end{array}$ \\
& $\begin{array}{l}\text { Neurology, UCLA Medical Center, } \\
\text { Los Angeles, CA }\end{array}$ & \begin{tabular}{l} 
\\
\hline
\end{tabular}
\end{tabular}

\section{References}

1. Lladó L, Baliellas C, Casasnovas C, et al. Risk of transmission of systemic transthyretin amyloidosis after domino liver transplantation. Liver Transpl 2010;16:1386-1392.

2. Stangou AJ, Hawkins PN. Liver transplantation in transthyretin-related familial amyloid polyneuropathy. Curr Opin Neurol 2004;17:615-620.

3. Liepnieks JJ, Zhang LQ, Benson MD. Progression of transthyretin amyloid neuropathy after liver transplantation. Neurology 2010;75:324-327.

4. Stangou AJ, Hawkins PN, Heaton ND, et al. Progressive cardiac amyloidosis following liver transplantation for familial amyloid polyneuropathy: implications for amyloid fibrillogenesis. Transplantation 1998;66:229-233.

5. Stangou AJ, Heaton ND, Rela M, Pepys MB, Hawkins PN, Williams R. Domino hepatic transplantation using the liver from a patient with familial amyloid polyneuropathy. Transplantation 1998;65:1496-1498.

6. Bergethon PR, Sabin TD, Lewis D, Simms RW, Cohen AS, Skinner M. Improvement in the polyneuropathy associated with familial amyloid polyneuropathy after liver transplantation. Neurology 1996;47:944-951.

7. Adams D, Koike H, Slama M, Coelho T. Hereditary transthyretin amyloidosis: a model of medical progress for a fatal disease. Nat Rev Neurol 2019;15: 387-404.

8. Koike H, Katsuno M. Ultrastructure in transthyretin amyloidosis: from pathophysiology to therapeutic insights. Biomedicines 2019;7:11.

9. Karlstedt E, Jimenez-Zepeda V, Howlett JG, White JA, Fine NM. Clinical experience with the use of doxycycline and ursodeoxycholic acid for the treatment of transthyretin cardiac amyloidosis. J Card Fail 2019;25:147-153.

10. Coelho T, Maia LF, Martins da Silva A, et al. Tafamidis for transthyretin familial amyloid polyneuropathy: a randomized, controlled trial. Neurology 2012;79:785-792. 


\section{Neurology}

\section{Pearls \& Oy-sters: Number, Weaker, and Dizzier Due to Transthyretin Amyloidosis After 2 Liver Transplants}

Alexan I. Yerevanian and Francy Shu

Neurology 2021;96;e1088-e1091 Published Online before print December 4, 2020

DOI 10.1212/WNL.0000000000011289

\section{This information is current as of December 4, 2020}

\section{Updated Information \&} Services

References

Subspecialty Collections

\section{Permissions \& Licensing}

Reprints including high resolution figures, can be found at: http://n.neurology.org/content/96/7/e1088.full

This article cites 10 articles, 3 of which you can access for free at: http://n.neurology.org/content/96/7/e1088.full\#ref-list-1

This article, along with others on similar topics, appears in the following collection(s):

Autonomic diseases

http://n.neurology.org/cgi/collection/autonomic_diseases Carpal tunnel syndrome

http://n.neurology.org/cgi/collection/carpal_tunnel_syndrome

EMG

http://n.neurology.org/cgi/collection/emg

Other Education

http://n.neurology.org/cgi/collection/other_education

Peripheral neuropathy

http://n.neurology.org/cgi/collection/peripheral_neuropathy

Information about reproducing this article in parts (figures,tables) or in its entirety can be found online at:

http://www.neurology.org/about/about_the_journal\#permissions

Information about ordering reprints can be found online:

http://n.neurology.org/subscribers/advertise

Neurology ${ }^{\circledR}$ is the official journal of the American Academy of Neurology. Published continuously since 1951, it is now a weekly with 48 issues per year. Copyright (C 2020 American Academy of Neurology. All rights reserved. Print ISSN: 0028-3878. Online ISSN: 1526-632X.

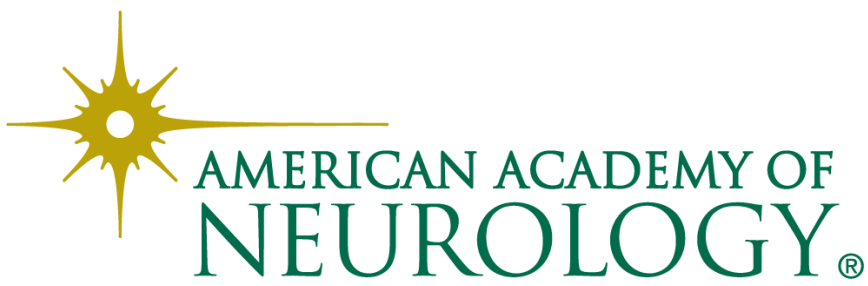

